\title{
Synthesis and characterization of undoped and sliver doped titanium dioxide thin film by using sol- gel spin coating method
}

\author{
[Mansoor Hussain, Tanveer Ashraf, Tahir Zaidi, Attaullah Shah, M. Quddamah]
}

\begin{abstract}
In this paper, structural and optical properties of undoped and sliver doped titanium dioxide film have been studied. By using Sol-gel method undoped and sliver doped titanium dioxide $\left(\mathrm{TiO}_{2}\right)$ thin film synthesis on FTO glass substrate. Sliver has been doped $3 \%, 7 \%$, concentration in titanium dioxide $\left(\mathrm{TiO}_{2}\right)$.Different properties such as, crystal structure, phase identification, thickness, band gap, transmission and absorption spectrum have been studied using X-ray diffraction (XRD), Raman spectroscopy, UV/Vis spectrophotometry. The results showed that undoped and Ag doped $\mathrm{TiO}_{2}$ thin film annealed at $450^{\circ} \mathrm{c}$ had anatase phases and there is no $\mathrm{Ag}$ peaks in $\mathrm{X}$-ray diffraction.
\end{abstract}

Keywords- Titanium dioxide, sliver, sol-gel spin coating, structural properties

\section{Introduction}

Titanium oxide is a semiconductor material having wide range of implementation in photo catalysis, corrosion protective coating, self-cleaning devices, gas sensor, energy storage and optical [1]. All these applications are based on morphology, crystallographic structure and physical properties of different phase of titanium. $\mathrm{TiO}_{2}$ can show three forms brookite, rutile and anatase as a bulk material while thin film of $\mathrm{TiO}_{2}$ can exhibit only rutile, anatase and amorphous. By using chemical deposition techniques brookite film can obtained using annealing temperature. Rutile is most stable phase and anatase and brookite can be transferred into rutile by annealing at high temperature [24]. Titanium dioxide has a band gap of $3.2 \mathrm{ev}, 3.0 \mathrm{ev}, 1.9 \mathrm{ev}$ for anatase, rutile and brookite respectively.

Titanium oxide is non toxic and chemically stable having electrochemical, exceptional physical, photoactive and electronic properties [5-8]. Due to its commercial and technological potential, much work has doing on this material [9, 10]. Titanium oxide involve in many applications such as water purification, lithium batteries, dielectric layer, gas sensing, solar cell, resistive switching etc [11-17]. Different method was adopted to increase their

Mansoor Hussain

National University of Sciences

and Technology, Pakistan

Tahir Zaidi

National University of Sciences and Technology, Pakistan

Muhammad Quddamah Khokhar

National University of Sciences

and Technology, Pakistan efficiency and applicability. By doping rear earth and transition metal in $\mathrm{TiO}_{2}$ thin film provides different changes in its structural and optical properties which is very beneficial for different applications. Silver is among most studied metal as dopant in $\mathrm{TiO}_{2}$ [18]. It gives better result and efficiency especially in antibacterial properties [19].

Because of this reason, numerous scientists have researched on the growth of thin films of $\mathrm{TiO}_{2}$ on the multiple substrates i.e. polycarbonate, glasses and copper by using different techniques such as vapor deposition, thermal oxidation and magnetron sputtering [20-22]. Table 1 is explaining the comparison of $\mathrm{Ag}$ doped $\mathrm{TiO}_{2}$ materials [2328]. In literature very little work is available on the $\mathrm{Ag}$ doped $\mathrm{TiO}_{2}$ specifically on the FTO template using the spin coating technique. In our study FTO templates were used and undoped, $3 \%$ and $7 \%$ sliver doped $\mathrm{TiO}_{2}$ films were synthesized by sol-gel spin coating method. optical and structural properties of undoped and sliver doped $\mathrm{TiO}_{2}$ were studied in detail.

\section{Experimental Method}

\section{A. Preparation of solutions}

0.12 mole solutions was prepared. Silver nitrate $\left(\mathrm{AgNO}_{3}\right)$ and titanium isopropoxide $\left(\mathrm{C}_{12} \mathrm{H}_{20} \mathrm{O}_{4} \mathrm{Ti}\right)$ precursors were used as initial materials to synthesize the undoped and sliver doped solutions. Specific molar ratios of precursors are measured for all Titanium based solutions. Firstly, 0.4 $\mathrm{ml}$ of titanium isopropoxide was hydrolyzed in $10 \mathrm{ml}$ ethanol under the magnetic stirring for $20 \mathrm{~min}$ under room temperature to get undoped solution. After that $1 \mathrm{ml}$ acetic acid was added in the solution and again stirred for $30 \mathrm{~min}$ at magnetic stirrer. For making the doped solution of $\mathrm{Ag}$ in $\mathrm{TiO}_{2}$, Sliver nitrate $\left(\mathrm{AgNO}_{3}\right)$ was used as additional precursor in simple $\mathrm{TiO}_{2}$ solution. $3 \%$ and $7 \%$ weighted used for doping and $6.98 \mathrm{mg}$ and $16.29 \mathrm{mg}$ sliver nitrate precursor used respectively. Sliver doped solution $\mathrm{TiO}_{2}$ solution stirrer for 4 hours at magnetic stirrer at room temperature.

\section{B. Deposition of $\mathrm{TiO}_{2}$ based films on substrates}

Different methods are available for thin film formation but the most simple and less expensive method which used for deposition of solution of silver doped and undoped on FTO template was sol-gel spin coating method. Before the deposition, substrate cleaning process was done. The FTO template was cleaned by an ultrasonic bath in acetone, poly ethylene glycol, ethanol and deionized water respectively, 
for each $15 \mathrm{~min}$. Drying process was done in air to remove any surface contamination. . After completing the cleaning process, Solution is spin coated at $3000 \mathrm{rpm}$ for $30 \mathrm{sec}$. After the deposition thin film is dried at $100^{\circ} \mathrm{C}$ for $10 \mathrm{~min}$. This cycle is repeated for 5 times. Annealing was done at $450^{\circ} \mathrm{c}$ for $30 \mathrm{~min}$ in air for good uniform films. Film thickness about100 $\mathrm{nm}$ in both undoped and sliver doped $\mathrm{TiO}_{2}$ films measured from Ellipsometry. Complete process explains in figure 1 .

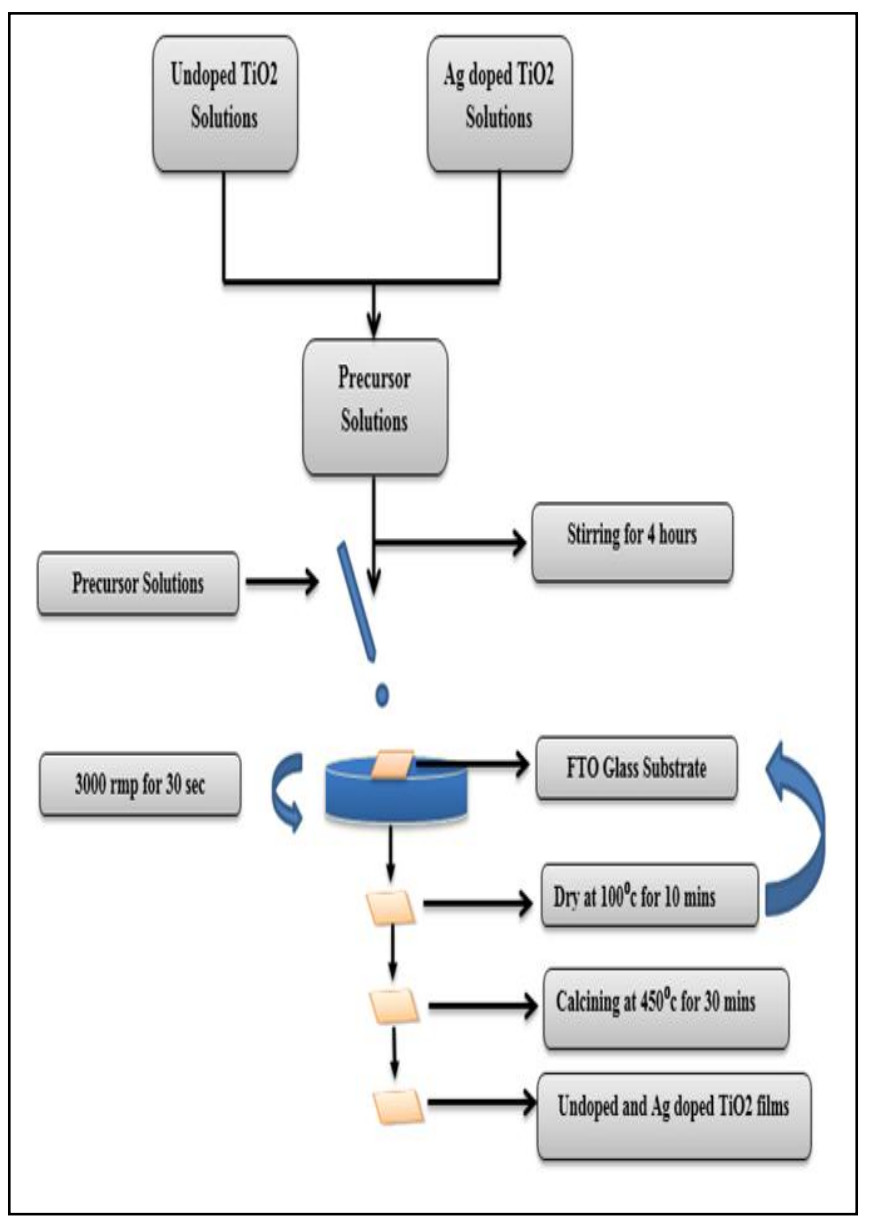

Fig.1.flow chart of spin coating method of undoped and sliver doped $\mathrm{TiO}_{2}$ films.

\section{Results and discussion}

\section{A. XRD Studies}

The crystal structure was examined by using X-Ray Diffraction. Figure 2 shows the patterns of undoped and Sliver Doped $\mathrm{TiO}_{2}$ using XRD. The $\mathrm{TiO}_{2}$ thin film that was synthesized by the sol-gel spin coating method showed the sharp and intense diffraction peaks at 25.40(101), 48.15(200), 54.67(211), 61.63(204) match with the JCPDS values (pdf card no: 00-021-1272) which correspond to anatase phase. . It is clear from XRD patterns that there are no characteristic peaks related to sliver or its oxides of $\mathrm{Ag}$ doped films. By increasing Sliver content intensities of peaks decreases and there is slight shift in peaks due to doping. It is reported that sliver doping improves the crystallization of Titanium dioxide in some cases, while decrease or remain same in other cases [29]. So, it can be examined that the intensities of film peaks showed very little decreasing tendency with increasing the Ag content. Instead of fact that there is a big variation between ionic radius of $\mathrm{Ti}^{4+}(74.5 \mathrm{pm})$ and $\mathrm{Ag}^{+}(129 \mathrm{pm})$ the existence of $\mathrm{Ag}$ content did not cause major varieties in crystallization. * represents the peaks of FTO Template.

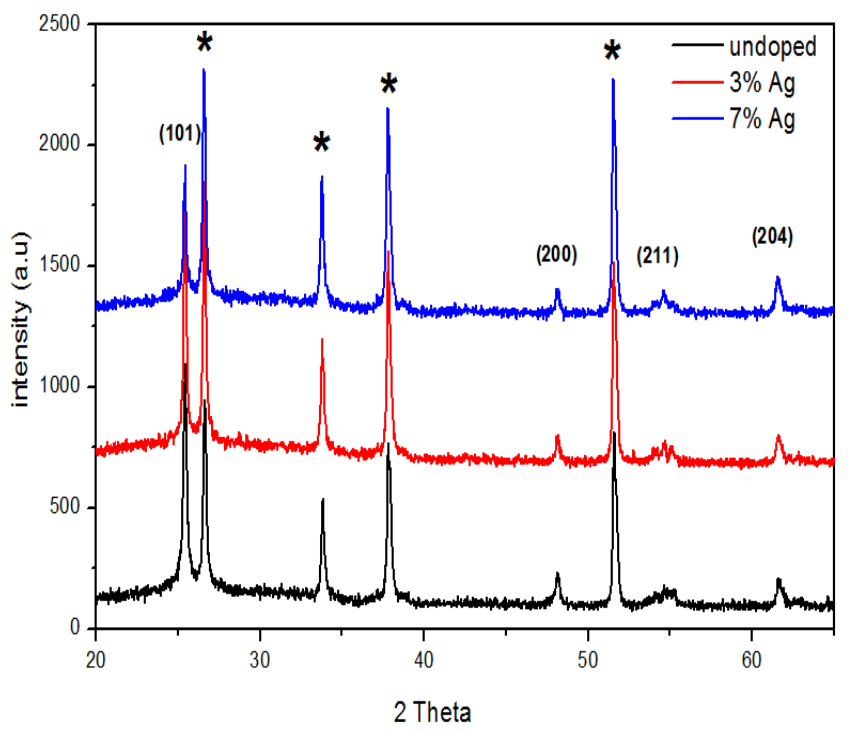

Fig.2. XRD patterns of $\mathrm{TiO}_{2}$ based films.

\section{B. Raman Spectroscopy}

To further clarify the structural study of undoped and Agdoped $\mathrm{TiO}_{2}$ obtain in XRD, Raman measurement were done at room temperature. Figure 3 displays Raman spectra of undoped and silver doped $\mathrm{TiO}_{2}$. Typically, Titanium dioxide anatase phase has four Raman vibrational phonon modes, named as $E_{g}, A_{1 g}, B_{1 g}$ modes [30]. Figure 3 clearly shows all four Raman vibrational phonon modes of Anatase phase at $148,390,510$, 632. There is no peak regarding to sliver or its oxides seen in Raman spectra. By increasing Sliver content Raman peaks width increases while intensity decreases which indicating degradation of crystalline quality of titanium dioxide thin film due to large size of $\mathrm{Ag}^{+}$ions.

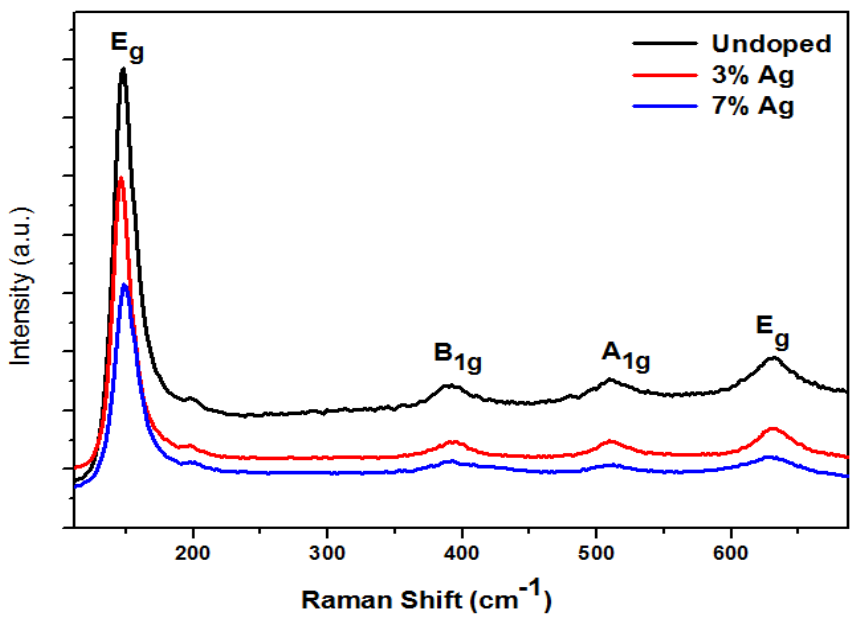

Fig.3. Raman spectra of $\mathrm{TiO}_{2}$ films. 


\section{Spectrophotometric studies}

The undoped and sliver doped $\mathrm{TiO}_{2}$ films were analyzed by UV-visspectroscopy. Figure 4 shows optical transmission spectra of the undoped and Sliver doped Titanium dioxide thin films in the visible region. Undoped $\mathrm{TiO}_{2}$ film is transmission is $\sim 35 \%$ and with the addition of $\mathrm{Ag}$ in $\mathrm{TiO}_{2}$ film transmission decreases due to structural defect created in the lattice. Overall low transmission rate is due to large thickness of films.

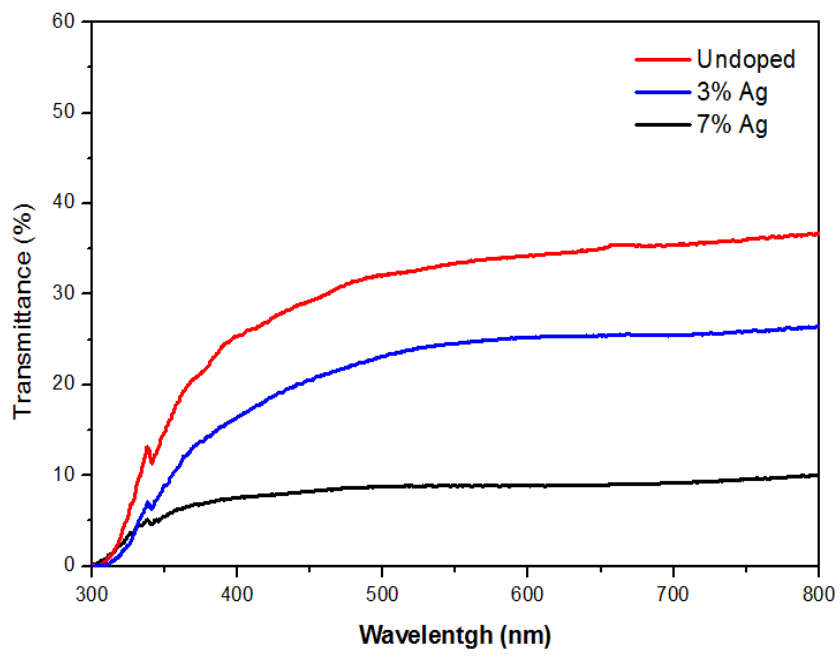

Fig.4. Transmission spectra of undoped and sliver doped $\mathrm{TiO}_{2}$ films.

Figure 5 shows the absorbance of undoped and sliver doped $\mathrm{TiO}_{2}$ films. Absorbance of both undoped and sliver doped $\mathrm{TiO}_{2}$ films sharp decrease in visible region $(>350 \mathrm{~nm})$. Doped films have smaller absorbance as compared to undoped film. Ag doping can have influence on absorption of light. Doping of Ag can have significantly influence on the absorption of light. By increasing doping amount, it is clear that in absorption spectra absorption edge shift.

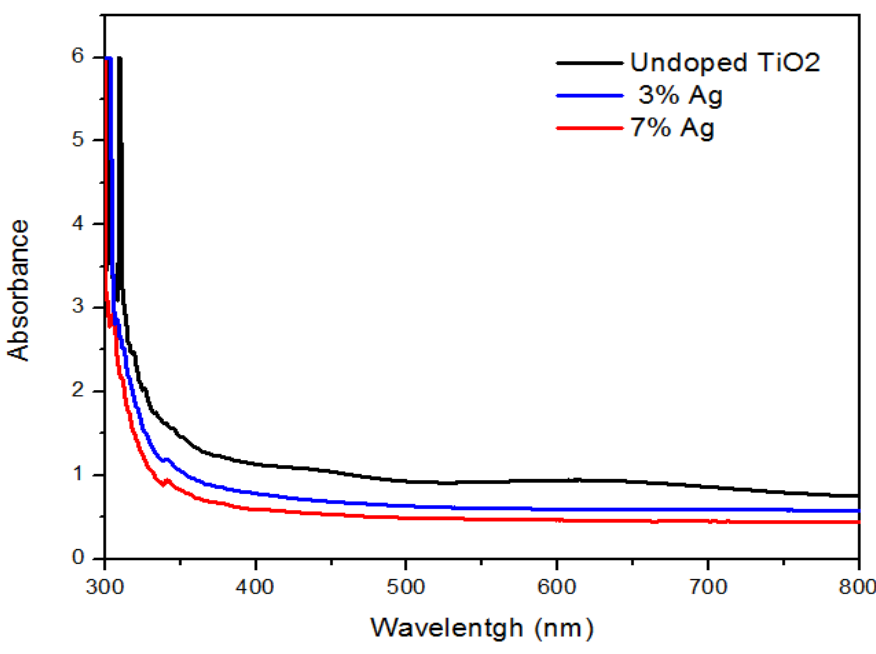

Fig.5. Absorbance spectra of undoped and sliver doped $\mathrm{TiO}_{2}$ films.
The band gap energy of undoped and sliver doped $\mathrm{TiO}_{2}$ thin films was calculated by using Tauc's relation for direct band gap material from transmission spectra.

$(\alpha h v)^{2}=\mathrm{A}\left(\mathrm{hv}-\mathrm{E}_{\mathrm{g}}\right)$

The absorption coefficient value was calculated using the relation

$\alpha=\frac{-\ln T}{t} \mathrm{~nm}^{-1}$

Here $\mathrm{t}$ represents thickness and $\mathrm{T}$ represent transmission spectra.

Table 1:

Band gap energy values of undoped and sliver doped $\mathrm{TiO}_{2}$ films.

\begin{tabular}{|c|c|}
\hline Film & $\mathrm{E}_{\mathrm{g}}(\mathrm{eV})$ \\
\hline undoped & $3.35 \mathrm{eV}$ \\
\hline $3 \% \mathrm{Ag}$ & $3.31 \mathrm{eV}$ \\
\hline $7 \% \mathrm{Ag}$ & $3.26 \mathrm{eV}$ \\
\hline
\end{tabular}

Band gap of undoped $\mathrm{TiO}_{2}$ is $3.35 \mathrm{eV}$ and sliver doped $\mathrm{TiO}_{2}$ films band gap energy of $3.33 \mathrm{eV}$ and $3.27 \mathrm{eV}$ for $3 \%$ and $7 \%$ sliver doping concentration respectively. Table 1 shows band gap of all films. Defective energy levels formed below conduction band are responsible of low band gap in sliver doped $\mathrm{TiO}_{2}$ and these defective energy levels formed due to structural defects. Since the structural defects are related to Ag concentration so band gap energy decreases slowly with the increasing of Ag concentration in Titanium dioxide thin films.

\section{Conclusion}

In this study, undoped and sliver doped $\mathrm{TiO}_{2}$ thin film prepared by low cost and simple sol-gel spin coating method. Structural properties were studies by XRD, Raman spectroscopy and optical properties studies using spectrophotometry. XRD and Raman shows that both undoped and sliver doped films in anatase phase with good crystalline structure. By increasing sliver content crystal quality decreases. The method used in this study is to provide a low cost, low temperature and simple synthesis of titanium dioxide thin film with good properties $\mathrm{TiO}_{2}$ thin film has large area of application from resistive switching to photo catalysis and sliver doped $\mathrm{TiO}_{2}$ also large area of applications. 


\section{References}

[1] Diebold, U. The surface science of titanium dioxide. Surface Science Reports 48, 53-229 (2003).

[2] Kuznetsova, I. N., Blaskov, V., Stambolova, I., Znaidi, L. \& Kanaev, A. $\mathrm{TiO} 2$ pure phase brookite with preferred orientation,

synthesized as a spin-coated film. Materials Letters 59, 3820-3823 (2005).

[3] Di Paola, A., Addamo, M., Bellardita, M., Cazzanelli, E. \& Palmisano, L. Preparation of photocatalytic brookite thin films. Thin Solid Films 515, 3527-3529, doi: 10.1016/j.tsf.2006.10.114 (2007).

[4] Moret, M. P., Zallen, R., Vijay, D. P. \& Desu, S. B. Brookite-rich titania films made by pulsed laser deposition. Thin Solid Films 366, $8-10(2000)$.

[5] L.A. Majewski, R. Schroeder, M. Grell, Low-voltage, highperformance organicfield-effect transistors with an ultra-thin $\mathrm{TiO} 2$ layer as gate insulator, Adv.Funct. Mater. 15 (2005) 1017-1022

[6] M. Matsui, M. Akaogi, Molecular dynamics simulation of the structural andphysical properties of the four polymorphs of $\mathrm{TiO}$, Mol. Simul. 6 (1991)239-244.

[7] F. Labat, P. Baranek, C. Domain, C. Minot, C. Adamo, Density functional theoryanalysis of the structural and electronic properties of $\mathrm{TiO} 2$ rutile and anatasepolytypes: performances of different exchange-correlation functionals, J.Chem. Phys. 126 (2007) 154703.

[8] H. Wang, J.P. Lewis, Effects of dopant states on photoactivity in carbon-dopedTiO2, J. Phys.: Condens. Matter 17 (2005) L209.

[9] T. Kamegawa, N. Suzuki, H. Yamashita, Design of macroporous TiO 2 thin filmphotocatalysts with enhanced photofunctional properties, Energy Environ.Sci. 4 (2011) 1411-1416.

[10] M. Takahashi, M. Inoue, R. Ihara, T. Yoko, T. Nemoto, S. Isoda, L. Malfatti, S.Costacurta, P. Innocenzi, Photo-fabrication of titania hybrid films withtunable hierarchical structures and stimuliresponsive properties, Adv. Mater.22 (2010) 3303-3306.

[11] Y. Xie, X. Zhao, Y. Chen, Q. Zhao, Q. Yuan, Preparation and characterization ofporous C-modified anatase titania films with visible light catalytic activity, J.Solid State Chem. 180 (2007) 3576-3582

[12] D. Li, H. Haneda, S. Hishita, N. Ohashi, Visible-light-driven NFcodoped TiO2photocatalysts. 2. Optical characterization, photocatalysis, and potentialapplication to air purification, Chem. Mater. 17 (2005) 2596-2602.

[13] V. Romeas, P. Pichat, C. Guillard, T. Chopin, C. Lehaut, Testing the efficacy andthe potential effect on indoor air quality of a transparent self-cleaningTiO2-coated glass through the degradation of a fluoranthene layer, Ind. Eng.Chem. Res. 38 (1999) 3878-3885.

[14] J.S. Chen, Y.L. Tan, C.M. Li, Y.L. Cheah, D. Luan, S. Madhavi, F.Y.C. Boey, L.A.Archer, X.W. Lou, Constructing hierarchical spheres from large ultrathinanatase $\mathrm{TiO} 2$ nanosheets with nearly $100 \%$ exposed (001) facets for fastreversible lithium storage, J. Am. Chem. Soc. 132 (2010) 6124-6130.

[15] M. Kumar, A.K. Gupta, D. Kumar, Mg-doped TiO2 thin films deposited by lowcost technique for $\mathrm{CO}$ gas monitoring, Ceram. Int. 42 (2016) 405-410.

[16] S.K. Kim, W.-D. Kim, K.-M. Kim, C.S. Hwang, J. Jeong, High dielectric constantTiO2 thin films on a Ru electrode grown at $250 \mathrm{C}$ by atomic-layer deposition,Appl. Phys. Lett. 85 (2004) 4112-4114.

[17] N.-G. Park, J. Van de Lagemaat, A. Frank, Comparison of dyesensitizedrutile-and anatase-based $\mathrm{TiO} 2$ solar cells, J. Phys. Chem. B 104 (2000)8989-8994.

[18] M. Behnajady, N. Modirshahla, M. Shokri, B. Rad, Enhancement ofphotocatalytic activity of $\mathrm{TiO} 2$ nanoparticles by silver doping:photodeposition versus liquid impregnation methods, Global Nest J. 10(2008) 1-7.

[19] B. Xi, L.K. Verma, J. Li, C.S. Bhatia, A.J. Danner, H. Yang, H.C. Zeng, $\mathrm{TiO} 2$ thinfilms prepared via adsorptive self-assembly for selfcleaning applications,ACS Appl. Mater. Interfaces 4 (2012) 10931102.

[20] M. Kitano, K. Funatsu, M. Matsuoka, M. Ueshima, M. Anpo, Preparation ofnitrogen-substituted $\mathrm{TiO} 2$ thin film photocatalysts by the radio frequencymagnetron sputtering deposition method and their photocatalytic reactivityunder visible light irradiation, J. Phys. Chem. B 110 (2006) 25266-25272
[21] D.H. Lee, Y.S. Cho, W.I. Yi, T.S. Kim, J.K. Lee, H.J. Jung, Metalorganic chemicalvapor deposition of TiO2: $\mathrm{N}$ anatase thin film on Si substrate, Appl. Phys. Lett.66 (1995) 815-816.

[22] C.-C. Ting, S.-Y. Chen, D.-M. Liu, Structural evolution and optical properties of TiO2 thin films prepared by thermal oxidation of sputtered Ti films, J. Appl.Phys. 88 (2000) 4628-4633.

[23] F. Bensouici, T. Souier, A.A. Dakhel, A. Iratni, R. Tala-Ighil, M. Bououdina,Synthesis, characterization and photocatalytic behavior of Ag doped TiO2 thinfilm, Superlattices Microstruct. 85 (2015) 255265.

[24] A. Guillén-Santiago, S.A. Mayén, G. Torres-Delgado, R. CastanedoPérez, A.Maldonado, M.d.1.L. Olvera, Photocatalytic degradation of methylene blueusing undoped and Ag-doped $\mathrm{TiO} 2$ thin films deposited by a sol-gel process:effect of the ageing time of the starting solution and the film thickness, Mater.Sci. Eng.: B 174 (2010) 84-87.

[25] C. He, Y. Yu, X. Hu, A. Larbot, Influence of silver doping on the photocatalyticactivity of titania films, Appl. Surf. Sci. 200 (2002) 239-247.

[26] J. Kaewkhao, P. Limsuwan, P.P.Y.P. Yupapin, S.J. JanJai, K. Ubonchonlakate, L.Sikong, F. Saito, ISEECPhotocatalytic disinfection of P.aeruginosa bacterialAg-doped TiO2 film, Procedia Eng. 32 (2012) 656-662.

[27] B. Xin, L. Jing, Z. Ren, B. Wang, H. Fu, Effects of simultaneously doped anddeposited $\mathrm{Ag}$ on the photocatalytic activity and surface states of TiO2, J. Phys.Chem. B 109 (2005) 2805-2809.

[28] X.F. Lei, X.X. Xue, H. Yang, Preparation and characterization of Agdoped $\mathrm{TiO}$ nanomaterials and their photocatalytic reduction of $\mathrm{Cr}(\mathrm{VI})$ under visible light,Appl. Surf. Sci. 321 (2014) 396-403.

[29] B.A. Akgun, C. Durucan, N.P. Mellott, Effect of silver incorporation oncrystallization and microstructural properties of sol-gel derived titania thinfilms on glass, J. Sol-Gel Sci. Technol. 58 (2011) 277-289.

[30] Huolin Huang, Yannan Xie, Zifeng Zhang, Feng Zhang, Qiang Xu,Zhengyun Wu, Growth and fabrication of sputtered $\mathrm{TiO} 2$ based ultraviolet detectors, Appl. Surf. Sci. 293 (2014) 248e254. 
Proc. of the Sixth International Conference on Advances in Computing, Electronics and Communication - ACEC 2017. Copyright (C) Institute of Research Engineers and Doctors. All rights reserved.

ISBN: 978-1-63248-138-2 doi: 10.15224/ 978-1-63248-138-2-06

About Author (s):

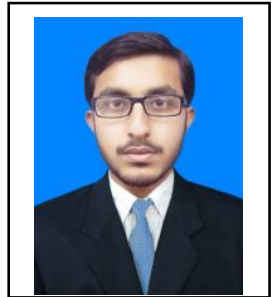

Mansoor Hussain received the B.Sc degree in Electrical Engineering from COMSATS Institute Of Information And Technology, Islamabad, Pakistan in 2015. Presently I am doing Master degree in Electrical Engineering at College of Electrical and Mechanical Engineering, National University of Sciences and Technology, Islamabad, Pakistan. My current area of research is resistive switching.

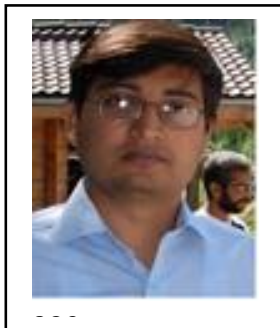

Tanveer Ashraf did his $\mathrm{PhD}$ from institute of semiconductor and solid state physics, Johannes Kepler University Linz Austria, in 2011. Presently he is working as associate professor in National institute of Laser and Optronics Islamabad.

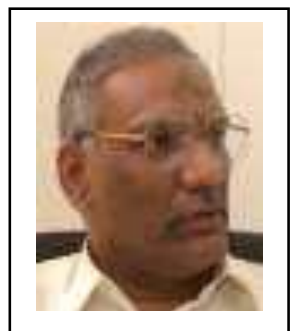

Tahir Zaidi received his Ph.D. degree from Georgia Institute of Technology, School of Electrical and Computer Engineering, United States in 2010 in Compound Semiconductors. Currently, he is Associate Professor with Department of Electrical Engineering, College of Electrical and Mechanical Engineering, National University of Sciences and Technology, Islamabad, Pakistan.

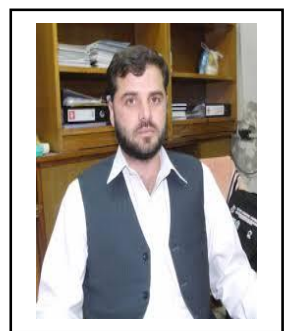

Attaullah Shah received his $\mathrm{PhD}$ from Pakistan institute of Engineering and Applied sciences Islamabad Pakistan, in 2014. Currently he is working as associate professor in National institute of Laser and Optronics Islamabad.

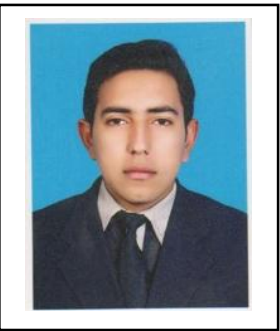

Muhammad Quddamah khokhar received the B.Sc degree in Electrical Engineering from Bahauddin Zakariya University, Multan, Pakistan in 2015. Presently he is working toward the Master degree in Electrical Engineering at College of Electrical and Mechanical Engineering, National University of Sciences and Technology, Islamabad, Pakistan. His current area of research is zinc oxide nanowires 